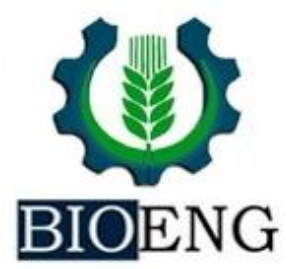

\section{EFEITO DO CAPIM VETIVER E DOS ESTILOZANTES NOS PARÂMETROS DE RESISTÊNCIA DO SOLO AO CISALHAMENTO}

\author{
D. A. C. Gomes ${ }^{1 *}$, G. M. C. S. Resende ${ }^{2}$, L. E. S. Dias ${ }^{3}$, P. L. T.
} Lima $^{4}$

\author{
${ }^{1}$ Universidade Federal Lavras (UFLA), Lavras, MG, Brasil \\ ${ }^{2}$ Centro Universitário Lavras (UNILAVRAS), Lavras, MG, Brasil \\ ${ }^{3}$ CentroUniversitário Lavras (UNILAVRAS), Lavras, MG, Brasil \\ ${ }^{4}$ University of California Davis, Davis, California, Estados Unidos
}

Article history: Received 06 March 2020; Received in revised form 27 March 2020; Accepted 27 March 2020; Available online 30 June 2020.

\title{
RESUMO
}

A resistência de cisalhamento de uma massa de solo é a resistência interna por área unitária que essa massa pode oferecer para resistir a rupturas e a deslizamentos ao longo de qualquer plano em seu interior. Uma das práticas existentes na tentativa de estabilização dos taludes envolve o cultivo de diferentes espécies vegetais. O objetivo deste trabalho é determinar os parâmetros de resistência ao cisalhamento do solo (coesão e o ângulo de atrito interno) de amostras de um solo sob efeito do desenvolvimento inicial do capim vetiver e dos estilozantes. São avaliados os efeitos em testemunha (solo nu) e solo sob cultivo do capim vetiver e estilozantes através de ensaios de cisalhamento direto do maciço. A hipótese do trabalho é avaliar o aumento da resistência do solo, garantindo a estabilidade do talude, portanto não serão necessários gastos adicionais com outras obras de contenção de custo mais elevado.

Palavras-chaves: ângulo de atrito interno, bioengenharia, compatibilidade ambiental, coesão do solo, sustentabilidade.

\section{EFFECT OF GRASS VETIVER AND STYLOSANTHES IN RESISTANCE PARAMETERS FROM THE SOIL TO THE SHEPHERD}

\begin{abstract}
The shear strength of a soil mass is the internal resistance per unit area that this mass can offer to withstand ruptures and landslides along any plane in its interior. One of there is practices in the attempt to stabilize slopes involves the cultivation of different plant species. The objective of this work is to determine the parameters of soil shear strength (cohesion and angle of internal friction) of soil samples under the initial development of the vetiver grass. The effects on control (bare soil) and soil under vetiver grass cultivation will be evaluated through direct soil shear tests. The hypothesis of the work is that the vetiver grass will increase the resistance of the soil ensuring a stabilization of the slope. Consequently, no additional costs will be required with other higher cost containment works.
\end{abstract}

Keywords: internal friction angle, bioengineering, environmental compatibility, soil cohesion, sustainability.

*diogogomes548@gmail.com 


\section{INTRODUÇÃO}

Há séculos, a engenharia utiliza da vegetação para o controle de processos erosivos, como proteção e reforço em obras civis.

A técnica de bioengenharia consiste na utilização de elementos biologicamente ativos em obras de estabilização dos solos e sedimentos. Estes elementos podem ser a vegetação combinada com elementos inertes, como rochas, concreto, madeira, ligas metálicas, polímeros naturais e sintéticos e geotêxteis (SCHIELTZ e STERN, 1996). A bioengenharia de solos, representada pelo uso de mantas de fibras vegetais (biotêxteis), como a fibra de coco, tem sido bastante utilizada e apresenta resultados satisfatórios.

Essas técnicas são empregadas para a estabilização de taludes e o controle dos processos erosivos. O uso das gramíneas traz muitos benefícios para o solo como por exemplo: manutenção da umidade do solo, aumento da estabilidade do talude e o aumento da infiltração de água no solo, reduzindo o escoamento superficial. Essa prática de contenção apresenta baixo custo, simples instalação e manutenção.

Há mais de três mil anos, o capim Vetiver é utilizado pela Índia e grande parte da Ásia para confecção de produtos artesanais, na fabricação de perfumes, medicamentos, repelente de insetos, entre outros (PEREIRA, 2006). Atualmente, ele surge como uma possível solução no controle da erosão.

Uma de suas qualidades é a facilidade de se desenvolver em solos

\section{MATERIAL E MÉTODO}

A área de estudo é situada próximo a cidade de Ingaí, no estado de Minas Gerais, em uma propriedade particular na zona rural situada com deficiência de nutrientes, entretanto quando comparado com outras gramíneas o tempo necessário para criar sua estrutura vegetal é elevado. A principal divergência se justifica por se tratar de um organismo vivo, que depende das condições como o tipo de solo, clima, nutrientes disponíveis para o seu desenvolvimento, uma vez que essas etapas influenciam na plantação.

Os estilozantes são leguminosas restauradoras da fertilidade dos solos que promovem a produção de grande quantidade de massa verde. O sistema é constituído pela raiz principal radicular, pivotante com predominância da raiz primária sobre as demais concorrendo expressivamente para maior agregação das partículas, ciclagem de nutrientes, aumento da capacidade de retenção de água, entre outros fatores físicos, além da proteção como cobertura, diminuindo as perdas por erosão (BONI et al.; 1994).

O capim Vetiver e os estilozantes possuem um vasto campo de aplicação, porém pouco conhecido. Este projeto tem como objetivo determinar os parâmetros de resistência ao cisalhamento direto (coesão e o ângulo de atrito interno) de amostras de um solo sob o efeito do desenvolvimento inicial e final das plantas.

A hipótese do trabalho é de que o capim Vetiver e os estilozantes são capazes de aumentar a resistência do solo garantindo a estabilidade do talude, portanto não serão necessários gastos adicionais com outras obras de contenção de custo mais elevado.

aproximadamente a $10 \mathrm{~km}$ da rodovia onde estão plantados o Vetiver e os estilozantes. No local foram coletadas amostras deformadas da classe de solo 
Latossolo, para posterior análise em laboratório.

As análises laboratoriais foram realizadas no laboratório de mecânica dos solos do Centro Universitário de Lavras, onde foram realizados os ensaios. Para testar as hipóteses apresentadas foram coletadas amostras deformadas, uma vez que o capim e os estilozantes foram cultivados em um solo de aterro. Os tratamentos avaliados são constituídos pelo solo nu e do solo sob cultivo do capim vetiver e dos estilozantes, sendo as amostras coletadas em profundidade $(0 \mathrm{~cm}-30 \mathrm{~cm})$, em concordância com a norma NBR 9.604/86.
Primeiramente foi avaliado o desenvolvimento do Vetiver em conjunto com as leguminosas. $\mathrm{O}$ estilozante é uma forrageira rica em proteína e nitrogênio. Suas principais características são: alta produtividade de sementes e ressemeadura, além de serem resistentes a solos mal drenados e auxiliarem na recuperação de áreas degradadas.

O Vetiver é uma planta que não necessita de solos com alto índice de matéria orgânica e quando combinado com as leguminosas, obtemos maior eficiência no crescimento das raízes. $\mathrm{Na}$ Figura 1 é mostrado o talude com o capim Vetiver e os estilozantes.

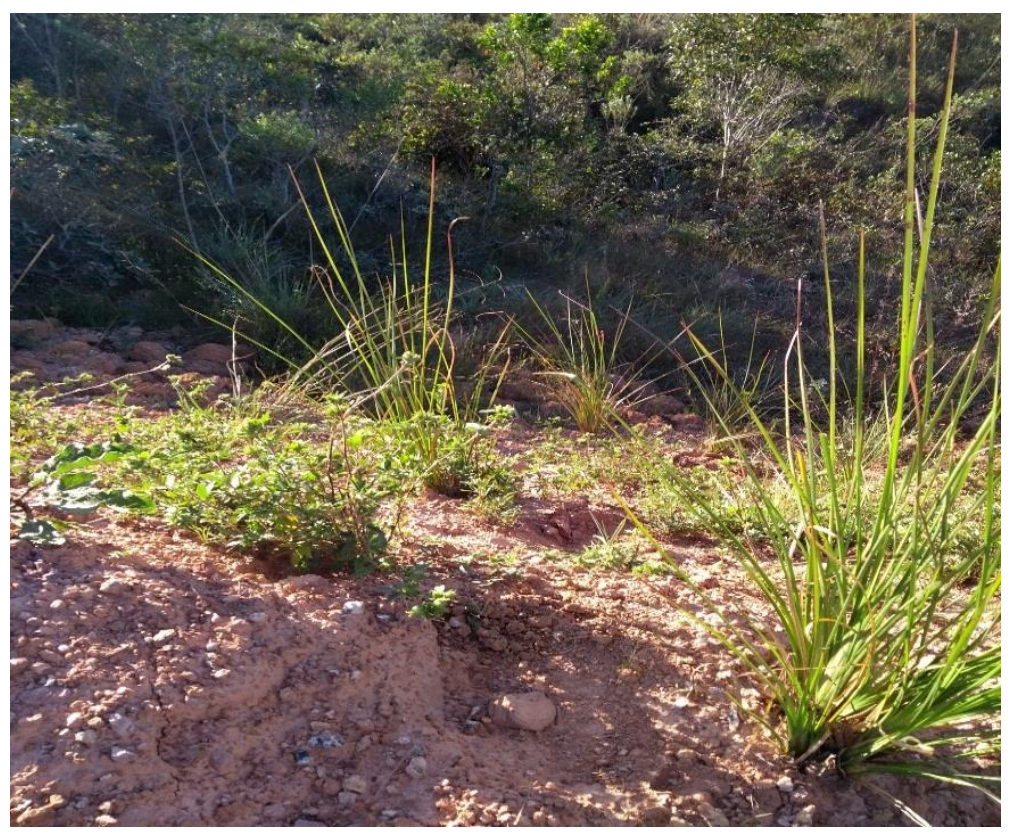

Figura 1. Capim vetiver e estilozante.

As figuras 2 e 3 apresentam o desenvolvimento das raízes do capim
Vetiver coletadas no segundo e no sexto mês, respectivamente. 


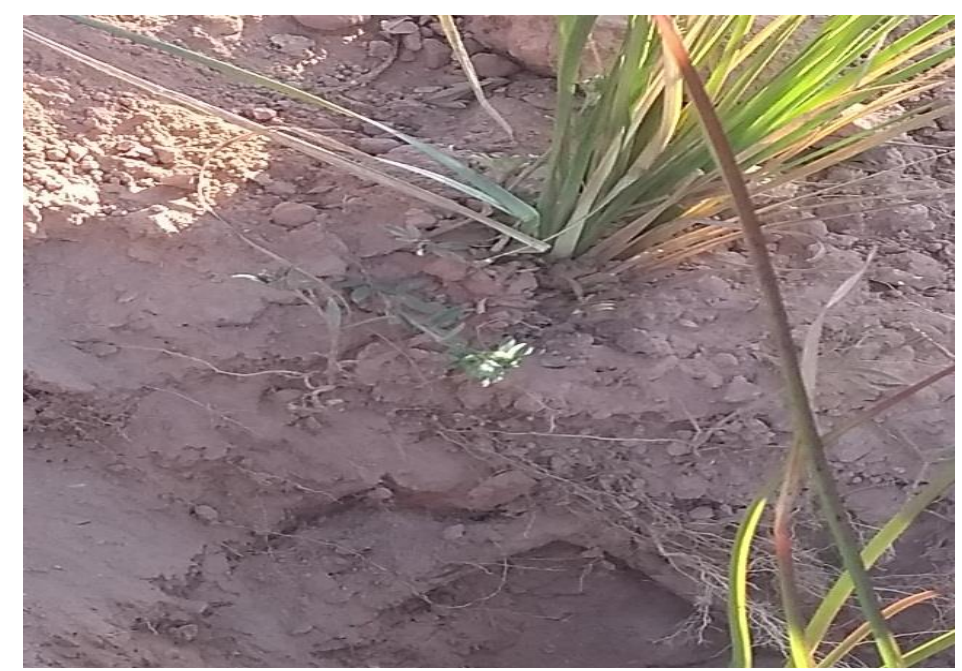

Figura 2. Capim vetiver segundo mês.

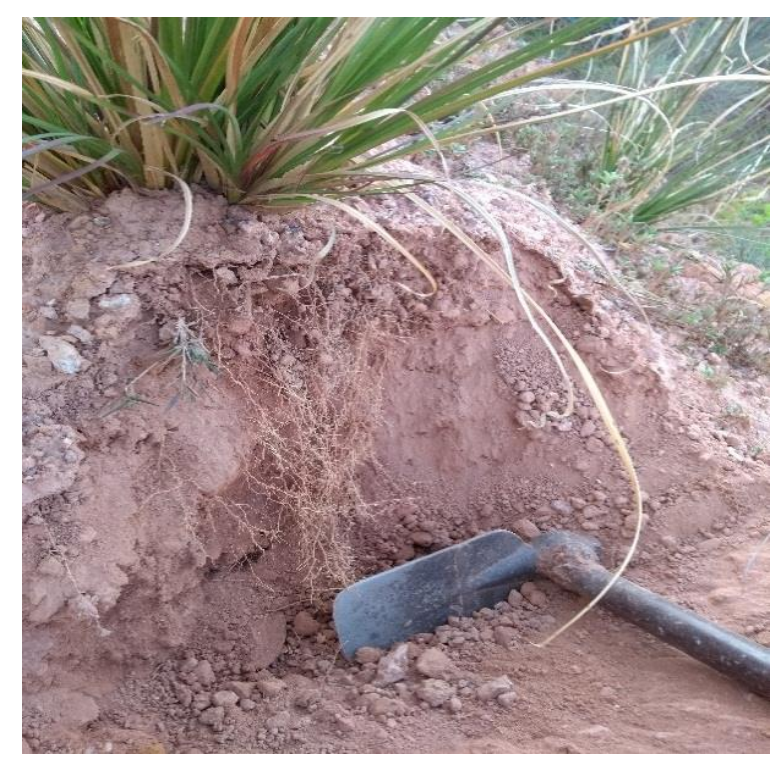

Figura 3. Capim vetiver sexto mês.

A utilização do capim Vetiver é ideal no ponto de vista ecológico e ambiental, uma vez que não é uma planta invasora e sua reprodução é exclusivamente realizada através de mudas (MADRUGA et al., 2007).

As leguminosas são capazes de formar associações simbióticas com bactérias fixadoras de nitrogênio no solo e apresentam raízes com arquitetura e profundidade que permitem maior estabilização do talude (PEREIRA, 2006).

A seguir será apresentado o resultado do desenvolvimento das plantas de estilozantes entre o segundo e o sexto mês. 


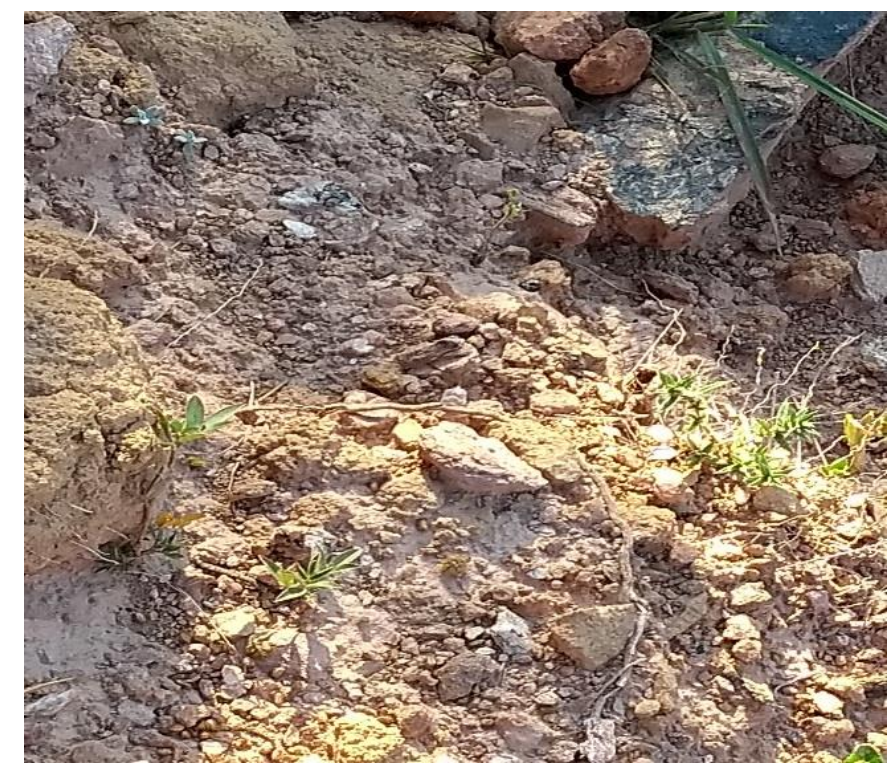

Figura 4. Estilozantes segundo mês

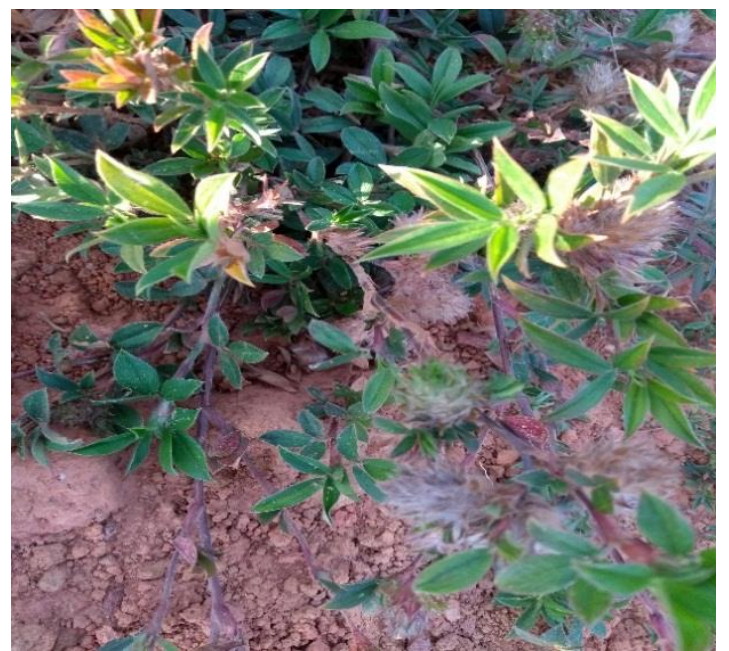

Figura 5. Estilozantes sexto mês

Outro aspecto importante na implantação da cobertura viva são as taxas de crescimento das leguminosas perenes, inicialmente lentas se comparadas às leguminosas anuais (PERIN et al; 2000). A cobertura viva protege o solo, mobiliza e recicla nutrientes, além de favorecer a atividade biológica no solo (GUERRA e TEIXEIRA, 1997; PERIN, 2001; DUDA et al., 2003).

O sistema radicular promove a estabilização das encostas, atuando sob dois aspectos principais; o mecânico e o hidráulico (GUIDICINI e NIEBLE, 1983). O aspecto mecânico pode se manifestar diretamente por meio da estruturação do solo, conferindo um acréscimo substancial de resistência ao cisalhamento e indiretamente pela continuidade de sua estrutura, formando uma malha de raízes, que distribui, na encosta, as tensões originadas em pontos críticos. $\mathrm{O}$ aspecto hidráulico pode se manifestar diretamente pelo estabelecimento de escoamento hipodérmico que desvia ou reduz a intensidade de infiltração no maciço. Indiretamente, como parte da ação biológica, esse sistema promove a sucção, com dois efeitos benéficos: Criação de pressão neutra e aumento da coesão do solo, resultando na redução de água que infiltra no maciço. 
Os testes foram realizados no equipamento de cisalhamento direto, com o objetivo de avaliar a capacidade resistente devido ao esforço cisalhante. $\mathrm{O}$ solo para o ensaio foi moldado em sessenta e um corpos de prova de dimensão $(58,70 \times 58,60$ x 17,79mm), diferenciados por amostras contendo as raízes das plantas e amostras com o solo nu, conforme mostrado na figura 6 .

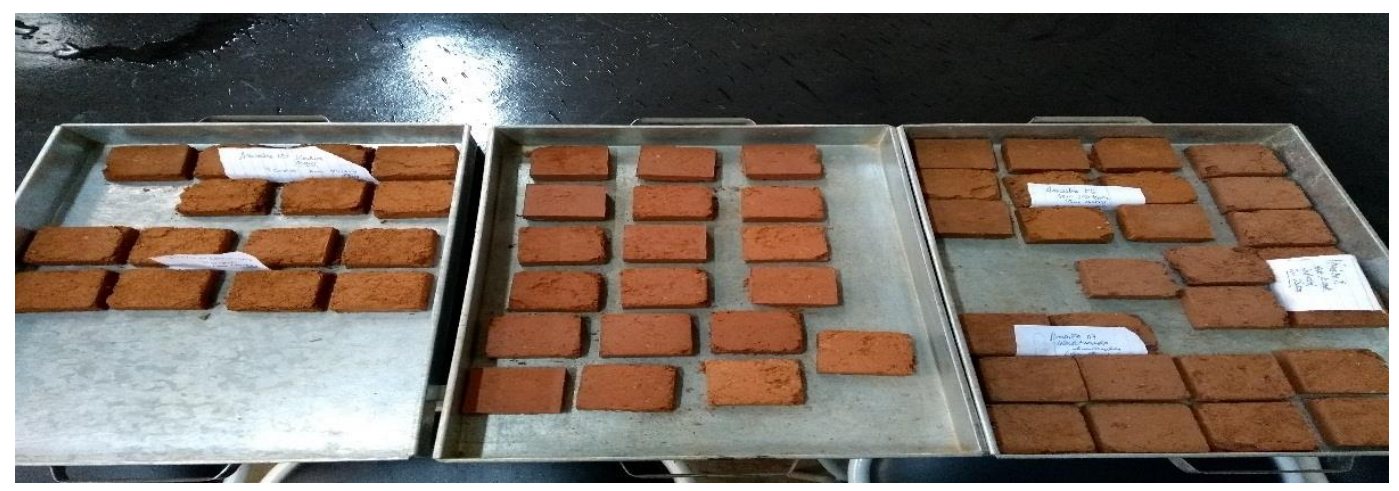

Figura 6. Corpos de prova.

Com os corpos de provas moldados foram realizados os ensaios e determinado o parâmetro de resistência ao cisalhamento das amostras de solo.

No ensaio de cisalhamento direto o solo é colocado em uma caixa composta por duas partes, uma inferior e a outra superior. Aplica-se uma força horizontal, para que ocorra o movimento relativo entre as duas metades da caixa e uma força vertical de cisalhamento submetendo à tensão máxima. A magnitude da força de cisalhamento é registrada em função do deslocamento horizontal e o deslocamento vertical representa o comportamento do solo durante o cisalhamento (LAMBE, 1969).

$\mathrm{Na}$ imagem a seguir está representada a caixa de cisalhamento, local onde foi colocado os corpos de prova para a realização dos ensaios, conforme a figura 7 .

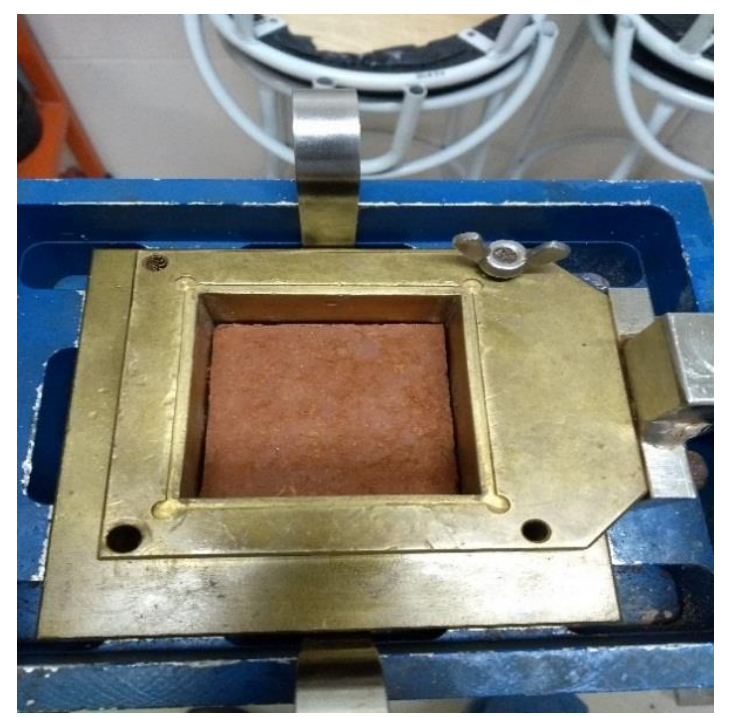

Figura 7. Caixa de cisalhamento.

Segundo Lambe (1969) o deslizamento entre partículas é o mecanismo mais importante nas deformações ocorridas dentro da massa de solo. Assim pode ser considerado que a resistência do solo à deformação é 
influenciada em grande parte pelo atrito nos contatos entre as partículas, embora este seja apenas um dos mecanismos responsáveis pela resistência ao cisalhamento de um solo. Considerando que se espera um comportamento não coesivo do material sobre o qual baseamos nosso estudo, daremos maior atenção neste trabalho à compreensão da parcela friccional da resistência ao cisalhamento e menor à parcela coesiva.

A figura 8 apresenta o corpo de prova após a realização do ensaio de cisalhamento direto, ou seja, com a ruptura do solo devido ao esforço aplicado.

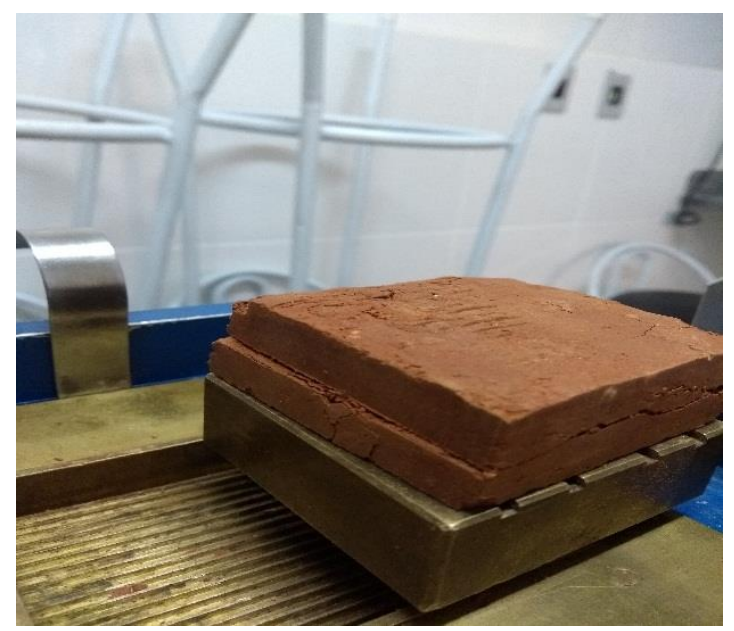

Figura 8. Bloco de solo cisalhado.

\section{RESULTADOS E DISCUSSÃO}

Foi possível observar que os estilozantes e o capim Vetiver tiveram bom desenvolvimento na região plantada. Os estilozantes, por terem um ciclo vegetativo menor, desenvolveu-se um pouco mais e o Vetiver já havia criado raízes consideráveis no solo, sendo a baixa umidade do solo um dos fatores predominantes para $\mathrm{o}$ desenvolvimento de ambas as vegetações. Além disso, não foram observadas pragas que pudessem causar patologias nas plantas e consequentemente influenciar nos resultados.

Houve um desenvolvimento considerável das raízes do capim vetiver. No segundo mês após o plantio apresentavam comprimento médio de $35 \mathrm{~cm}$, no sexto mês as raízes alcançaram o comprimento médio de $80 \mathrm{~cm}$ de profundidade, ou seja, mais que dobrou de tamanho em relação à primeira análise do capim. Além disso, o capim estava formando uma rede densa conforme mostrado nas literaturas.

As raízes dos estilozantes no segundo mês pós plantio apresentavamse com comprimento médio de $16 \mathrm{~cm} \mathrm{e}$ no sexto mês estavam com média de $38 \mathrm{~cm}$. Outro fator importante é a criação da camada vegetal e o seu desenvolvimento nesse período. Essa planta apresenta a produção de sementes, com isso a atuação do vento faz com que ocorra a semeadura ao longo do talude e consequentemente temos uma rapidez na criação da camada vegetal.

Para confecção dos corpos de prova a serem ensaiados foi necessário a adição de água de acordo com a NBR 6457.

Na Tabela 1 é mostrado quantidade de solo e a respectiva quantidade de água necessária para moldar o corpo de prova. $\mathrm{O}$ ensaio para 
obter a umidade ótima foi realizado através do ensaio de compactação e foi obtida umidade ótima de $15 \%$. Ressaltase que os corpos de prova são provenientes da região com e sem a presença do capim vetiver, o mesmo serve para estilozantes, tornando possível avaliar um possível ganho de resistência ao cisalhamento devido a presença das vegetações.

Tabela 1. Quantidade de água para moldar o corpo de prova.

\begin{tabular}{ccc}
\hline Amostra & $\begin{array}{c}\text { Quantidade de solo para fazer o molde } \\
(\mathrm{g})\end{array}$ & Quantidade de água $(\mathrm{g})$ \\
& 400 & 60 \\
Ventiver & 400 & 60 \\
Estilozantes & 400 & 60 \\
Sem raizes & &
\end{tabular}

Para o ensaio de cisalhamento direto os corpos de provas foram ensaiados na caixa de cisalhamento com a utilização de duas pedras porosas e foi realizado a leitura nos extensômetros do anel dinâmico e do deslocamento da caixa de cisalhamento.

As curvas de tensão cisalhante versus tensão normal, correspondentes às envoltórias de resistência ao cisalhamento, de amostras de solo com diversos tratamentos, com a presença de raízes do vetiver (Chrysopogon zizanioides (L.) Roberty) ou de estilosantes (Stylosanthes guianensis (AUBL) SW. CV "COOK").

Os parâmetros de resistência ao cisalhamento de Mohr-Coulomb para as amostras analisadas apresentaram elevadas variações (Tabela 2). Os parâmetros de resistência avaliados são o ângulo de atrito interno (inclinação da reta) e o intercepto de coesão (valor da tensão cisalhante quando a reta corta o eixo das tensões cisalhantes).

Tabela 2. Parâmetros de resistência ao cisalhamento do solo em amostras de solo (0 - 30 $\mathrm{cm}$ ) com e sem a presença de capim vetiver (Chrysopogon zizanioides (L.) Roberty) ou estiliozantes (Stylosanthes guianensis (AUBL) SW. CV "COOK").

\begin{tabular}{cccc}
\hline Tratamento & $\begin{array}{c}\text { Ângulo de atrito } \\
\text { interno }\left(^{\circ}\right)\end{array}$ & $\begin{array}{c}\text { Intercepto de } \\
\text { coesão }(\mathrm{kPa})\end{array}$ & $\begin{array}{c}\text { Coeficiente de } \\
\text { Determinação }\end{array}$ \\
\hline Sem raízes & $0,63^{\circ}$ & 1,0463 & $12,34 \%$ \\
Capim Vetiver & $1,02^{\circ}$ & 2,4133 & $57,33 \%$ \\
Estilosantes & $1,85^{\circ}$ & 1,1916 & $42,06 \%$ \\
\hline
\end{tabular}

Os dados apresentados na tabela 2 permitem observar o aumento da coesão e do ângulo de atrito interno do solo com plantio de capim vetiver e dos estiliozantes, resultando no aumento da resistência ao cisalhamento de solos sob desenvolvimento inicial do capim vetiver, apesar do delimitado tempo de estudo do período. Com o tratamento dos estilozantes obtivemos um aumento de $65,95 \%$ ao ângulo de atrito e $12,19 \%$ na coesão, quando comprados com o 
tratamento sem raízes. Já com o capim vertiver houve um aumento $38,23 \%$ no ângulo de atrito e 56,64\% na coesão, quando comparados com o tratamento sem raízes. Tais resultados corroboram com taludes avaliados em Santana dos Montes, Minas Gerais, onde o cultivo do capim vetiver aumentou a resistência do solo após três anos de cultivo, auxiliando na estabilização dos taludes (BARBOSA; LIMA, 2013).

As envoltórias de resistência ao cisalhamento para todas as tensões estudadas, apresentaram uma inclinação constante ao longo de toda a faixa de pressões normais utilizadas. A fraca agregação deste solo, especialmente na sua camada superficial, justifica tais resultados, assim, os agregados não apresentam resistência suficiente para produzir mudanças significativas na inclinação e no intercepto da envoltória (LEBERT; HORN, 1991).

Os resultados obtidos devido a influência do capim vetiver em amostras de solo submetidas a diferentes forças normais aplicadas $(19,5 ; 30,55 ; 41,66 \mathrm{e}$ $52,77 \mathrm{kPa})$ foram analisados estatisticamente pelo TESTE T. A diferença significativa ( $p$-valor abaixo de 0,05$)$ entre as amostras em todas as forças normais aplicadas evidencia a influência do desenvolvimento inicial do capim vetiver nos parâmetros de resistência do solo. As raízes do capim se adaptam a diversos tipos de terrenos, podendo penetrar no solo em grandes profundidades, elevando a resistência do mesmo (FEITOSA, 2017).

\section{CONCLUSÃO}

A presença de raiz do capim vetiver no solo proporciona no maciço os parâmetros de resistência (intercepto de coesão e ângulo de atrito interno), por isso podemos considerar que houve um aumento de resistência do capim por apresentar um ano de idade e com o
Assim como no capim vetiver, foram analisadas estatisticamente pelo TESTE $\mathrm{T}$ a influência de estilosantes em amostras de solo submetidas a diferentes forças normais aplicadas $(19,5 ; 30,55$; $41,66$ e $52,77 \mathrm{kPa})$. Os valores apresentados indicam uma diferença significativa baixa ( $\mathrm{p}$-valor acima de $0,05)$ entre as amostras avaliadas nas forças aplicadas de 19,5; 30,55; 41,66 $\mathrm{kPa}$. Desta maneira não foi possível observar qualquer influência do estilosante nos parâmetros de resistência do solo durante o período de estudo avaliado. A influência do mesmo é discutida na literatura (ALENCAR et al., 2010; NEGREIROS NETO et al., 2010; FERREIRA et al., 2018), sendo recomendado um maior período de pesquisa para que o efeito do mesmo possa ser mais preciso.

Em relação ao solo analisado os estilozantes tem ciclo produtivo muito rápido por isso é formada uma maior cobertura vegetal no solo e isto traz benefícios a raiz do vetiver, já que com uma maior camada vegetal é possível manter a umidade da raiz do vetiver durante o período de maiores estiagens sem comprometer o seu desenvolvimento nesse período.

O solo em estudo é proveniente de um aterro, por este motivo as partículas do solo estão muito soltas ocorrendo um desgaste na camada de solo. Observa-se também que o solo está apresentando um aumento da camada vegetal.

decorrer do tempo haverá um número maior de raízes presentes no solo.

Para ajudar no combate da erosão do solo junto com o vetiver foram plantados os estilozantes, uma das suas principais funções é aumentar a camada vegetal e o número de nutrientes no solo. 
As plantas que foram utilizadas nessa pesquisa não precisam de muita matéria orgânica e nutrientes do solo, uma vez que o resultado das análises realizadas no maciço não apresentava muitos nutrientes.

Ao longo desta pesquisa, a contribuição oferecida ao solo pelas raízes do vetiver e dos estilozantes que foram ensaiadas, por meio de cisalhamento direto, comprovam o

\section{REFERÊNCIAS BIOGRÁFICAS}

ABNT. ASSOCIAÇÃO BRASILEIRA DE NORMAS TÉCNICAS. NBR 9.604: Abertura de poço e trincheira de inspeção em solo, com retirada de amostras deformadas $e$ indeformadas. Rio de Janeiro, 1986.

ABNT. ASSOCIAÇÃO BRASILEIRA DE NORMAS TÉÇNICAS. NBR 6457: Amostras de solo- Preparação para ensaios de compactação e Ensaios de caracterizaçãa. Rio de Janeiro, 1986.

ALENCAR, C. A. B. de; OLIVEIRA, R. A. de; CÓSER, A. C.; MARTINS, C. E.;

FIGUEIREDO, J. L. A.; CUNHA, F. F. da. (2010) Produção de seis capins manejados por pastejo sob efeito de diferentes doses nitrogenadas e estações anuais. Revista Brasileira de Saúde e Produção Animal, 11, 48-58.

BARBOSA, M. C. R., LIMA, H. M. (2013). Resistência ao cisalhamento de solos e taludes vegetados com capim vetiver. Revista Brasileira de Ciência do Solo, 37(1), 113-120.

BONI, N.R; ESPINDOLA, C.R; GUIMARÃES, E.C. Uso de leguminosas na recuperação de um solo decapitado. In: SIMPÓSIO NACIONAL DE RECUPERAÇÃO DE ÁREAS DEGRADADAS, 1., 1994, Foz aumento de resistência ao cisalhamento do solo. Neste sentido foram consideradas algumas hipóteses e alguns fatores que podem ser melhorados em futuras pesquisas: Realização de ensaio de cisalhamento direto com corpos de prova maiores, maior número de ensaios e plantio por um período mínimo de um ano.

do Iguaçu. Anais... Curitiba:

UFPR/FUPEF, 1994. P.563-568.

DUDA, G.P. et al. Perennial herbaceous legumes as live soil mulches and their effects on $\mathrm{C}, \mathrm{N}$ and $\mathbf{P}$ of the microbial biomass. Sci. Agric.; v.60, n.1, p.139-147,2003.

FEITOSA, A. D. (2017). A influência do Vetiver nos parâmetros de resistência do solo, coesão e ângulo de atrito. Monografia (Graduação). Universidade Federal de Ouro Preto (UFOP) Departamento de Engenharia Civil.

FERREIRA, C. J. B., TORMENA, C. A., CECATO, U., FRANCO, H. H. S., MOREIRA, W. H., GALBEIRO, S., RIBEIRO, O. L. (2018). Soil physical properties under a 'Tanzânia' grass pasture fertilized with mineral nitrogen or intercropped with stylosanthes. Pesq. Agropec. Bras., Brasília, 53(4), 478-486.

GUERRA, J.G.M.; TEXEIRA, M.G. Avaliação inicial de algumas leguminosas herbáceas perenes para utilização como cobertura viva permanente de solo. Seropédica: Embrapa-CNPAB, 1997. 7 p. (comunicado técnico, 16). 
GUIDICINI, G.; NIEBLE, C.M.

Estabilidade de taludes naturais e de escavação. São Paulo: Edgard Blucher, 1983. 211p.

LAMBE, T. W., WHITMAN, R. V., 1969, Soil Mechanics. New York, John Wiley \& Sons.

LEBERT, M.; HORN, R. A method to predict the mechanical strength of agricultural soils. Soil Tillage Res, v.19, p.275- 286, 1991.

MADRUGA, E. L.; SCHELE, E. L. \& SALOMÃO, F. X. T. (2007). Uso do capim vetiver (sistema vetiver) na estabilização de taludes de rodovias, proteção de drenagens e de áreas marginais. Disponível em: http://www.iwfplanet.com/arquivos/Pes quisa_Vetiver(1).pdf. 25p. Acesso em outubro de 2018.

PEREIRA, A. R.. Uso do Vetiver na Estabilização de taludes e Encostas. Boletim Técnico, ano 01, n003. Belo Horizonte. Editora FAPI Ltda., 2006. $22 \mathrm{p}$.

PERIN, A. Desempenho de leguminosas herbáceas perenes com potencial de utilização para cobertura viva e seus efeitos sobre alguns atributos físicos do solo. 2001. $144 \mathrm{f}$. Dissertação (Mestrado em ciências do solo) - Universidade Federal Rural do Rio de Janeiro, Seropédica, 2001.

PERIN, A.; TEXEIRA, M.G.; GUERRA, J.G.M. Desempenho de algumas leguminosas com potencial para utilização como cobertura viva permanente de solo. Agronomia, v.34, n. 1/2, p.38-43, 2000.

SCHIELTZ, H.M.; STERN, R. Ground bioengineering techniques for slope protection and erosion control. [ s.l.]: Blackwell Science, 1996. 186.p. 